\title{
SUBLINGUAL MIDAZOLAM AS A PREMEDICATION FOR CONSCIOUS SEDATION DURING MINOR GYNAECOLOGICAL PROCEDURE AT TERTIARY CARE CENTRE LOCATED AT RURAL AREA OF MAHARASHTRA, WESTERN INDIA
}

\author{
Jaya Dighe ${ }^{1}$ \\ ${ }^{1}$ Associate Professor, Department of Anaesthesia, SBH Government Medical College, Dhule, Maharashtra.
}

ABSTRACT
BACKGROUND
Most of the minor procedures are performed under local anaesthesia. Conscious sedation is an appropriate choice. In various
studies, Midazolam as a premedication found to be very effective, short acting, safe, profound amnesic properties. Along with
intravenous administration, other routes like oral, intranasal and sublingual has been found to be effective. Sublingual route bypasses
the first pass hepatic metabolism due to rich blood supply of oral mucosa.

\section{AIMS}

To evaluate the efficacy of optimum dosage of sublingual midazolam for conscious sedation for minor gynaecological procedures.

\section{METHODS}

The present prospective double blind study carried out at Anaesthesia Department of a Tertiary Care Hospital during 2013. It included the cases with age group (20-60 yrs.), weight (40-60 kg), ASA Grading I and II, normotensive patients undergoing elective minor gynaecological procedure. Midazolam sublingual $(0.5 \mathrm{mg} / \mathrm{kg})$ and oral $(0.5 \mathrm{mg} / \mathrm{kg})$ were given to Group A and Group B respectively by allocating it randomly to 30 participants for each group. Observer's Assessment of Alertness/Sedation Scale (OAA/S) and four point anxiolysis scale was used. For statistical analysis, sedation and anxiolysis score is dichotomized into two groups like $\leq 17$ and $>17$ for sedation and $\geq 3$ and $<3$ for anxiolysis.

\section{RESULTS}

30 cases from each group matched with clinical demographic profile was included during the study period. Measurable sedation $\leq 17$ score was achieved among $26(86.6 \%)$ of the participants at 30 minutes of administration of sublingual midazolam, ( $p=0.03)$. Also, anxiolysis score, i.e. $\geq 3$ was observed among 28 (93.3\%) participants of Group A at 30 minutes of administration of sublingual midazolam, $(\mathrm{p}=0.02)$.

\section{CONCLUSION}

In conclusion, use of midazolam for conscious sedation as well as anxiolysis is more effective through sublingual route as compared to oral route for minor procedures in gynaecology.

\section{KEYWORDS}

Conscious Sedation, Minor Gynaecological Procedure, Midazolam, Sublingually.

HOW TO CITE THIS ARTICLE: Dighe J. Sublingual midazolam as a premedication for conscious sedation during minor gynaecological procedure at tertiary care centre located at rural area of Maharashtra, Western India. J. Evolution Med. Dent. Sci. 2016;5(42): 2631-2633, DOI: $10.14260 /$ jemds/2016/615

\section{INTRODUCTION}

Minor procedures in obstetrics and gynaecology constitutes majority of operations. Most of them are performed under local anaesthesia, so as to minimize stress associated with the operative room environment. An important concern in anaesthesia is prompt recovery. Conscious sedation is an appropriate choice for patients who do not require a general anaesthetic, but rather need sedation to alleviate anxiety, minimize the discomfort of less invasive surgical procedures or even to tolerate a regional or local anaesthetic. ${ }^{1}$

Although, the American College of Obstetrician and Gynaecologist (ACOG) and the American Society of

Financial or Other, Competing Interest: None.

Submission 10-03-2016, Peer Review 04-05-2016,

Acceptance 10-05-2016, Published 26-05-2016.

Corresponding Author:

Dr. Jaya Dighe,

Department of Anaesthesia,

SBH Government Medical College,

Dhule-424001,

Maharashtra.

E-mail: drjayadighe@yahoo.com

DOI: $10.14260 /$ jemds/2016/615
Anaesthesiologists (ASA) have established goals to ensure prompt provision of anaesthetic services in all hospitals, it remains a challenge, particularly in smaller hospitals or in rural locations. ${ }^{2}$ In various studies comparing midazolam, a newer fused ring benzodiazepine with other drugs like diazepam, ketamine, morphine, fentanyl, sufentanyl, promethazine and pethidine, it was found to be very effective, short acting, safe, and also was found to have profound amnesic properties, haemodynamic stability and lesser respiratory depression. 3,4

Midazolam is rapidly absorbed when administered orally either as premixed syrup or by diluting the intravenous formulation in a $\mathrm{pH}$-balanced, palatable, liquid vehicle (eg. apple juice). It has an oral bioavailability of 35 to $44 \%$ with an onset of action within 15-30 minutes and peak plasma levels achieved within 20-50 minutes. $^{5}$ Along with intravenous administration, other routes like oral, intranasal and sublingual were found to be effective. Sublingual route bypasses the first pass hepatic metabolism due to rich blood supply of oral mucosa. Hence, the present study conducted with objective to evaluate the efficacy of optimum dosage of sublingual midazolam for conscious sedation for minor gynaecological procedures. 


\section{MATERIALS AND METHODS}

The present prospective double blind study carried out at Anaesthesia Department of Tertiary Care Hospital located at a rural area of Maharashtra during 2013.

The study included the cases with age group (20-60 yrs.), weight (40-60 kg), ASA Grading I and II, normotensive patients undergoing elective minor gynaecological procedure. Cases with $>60$ yrs. or $<20$ yrs. of age, weight $>60 \mathrm{~kg}$, medical disorder like heart disease, Type 1 and Type 2 diabetes, anaemia, allergy, bronchial asthma, patient on medication for CNS disorder, psychiatric patients, suffering from liver disease, oral pathology, also renal disease and narrow angle glaucoma as absolute contraindications were excluded from the study. Institutional Ethical Committee approval was taken prior to study.

The study was conducted between January-June 2013 to achieve the total of 60 participants. Written informed consent was obtained. All selected patients underwent routine investigations which include haemoglobin, complete blood count, blood sugar level (random), bleeding time, clotting time, urine examination, chest X-ray. The age, sex, weight, pulse rate, respiratory rate, blood pressure and oxygen saturation were recorded preoperatively. Sublingual midazolam $(0.5 \mathrm{mg} / \mathrm{kg})$ or oral midazolam $(0.5 \mathrm{mg} / \mathrm{kg})$ were given to Group A and Group B respectively by allocating it randomly to 30 participants for each group. Patients were advised not to swallow the drug given for sublingual administration.

Observer's Assessment of Alertness/Sedation Scale (OAA/S) was used for sedation. Scores were obtained and recorded on 20 point scale. Measurable sedation was defined as a score of 17 or less on the 20-point scale. Also, clinical scale based on following four points was used to assess anxiolytic effects: (1) Tearful or Combative; (2) Anxious, but easily reassured; (3) Calm; (4) Asleep. Satisfactory anxiolysis was considered for score more than or equal to 3; (5) The sedation and anxiolysis score to be recorded every 15 minutes till 60 minutes after administration. The observers were unaware about the medication to be administered. All the patients were monitored intra-operatively for pulse rate and blood pressure. In recovery room, patient is put on the IV cannulation. Anaesthetic drugs with emergency drugs, endotracheal tubes, laryngoscope and other resuscitative measures kept ready.

All the data entered, cleaned and analysed using MS Excel 2010. Mean \pm standard deviation was used for comparing both the groups. For statistical analysis, sedation and anxiolysis score is dichotomized into two groups like $\leq 17$ and $>17$ for sedation and $\geq 3$ and $<3$ for anxiolysis. The GraphPad Prism Software was used for statistical analysis.

\section{RESULTS}

Total 60 cases were included during the study period. The participants' characteristics including age and weight were compared among the two groups for any variation. Age wise distribution shows mean age group of $41.8 \mathrm{yrs}$. [S.D. 5.2 (Range 27-55 yrs.)] and 43.8 yrs. [S.D. 7.1 yrs. (Range 29-57 S.D. 7.1)] among Group A and B respectively. ( $\mathrm{P}=0.14$, statistically not significant). While weight wise $55.08 \mathrm{~kg}$ [S.D. 7.43 (Range 4070 yrs.)] and $51.15 \mathrm{~kg}$ [S.D. 10.1 (Range 28-68 yrs.)] distribution was seen among Group A and B respectively. ( $\mathrm{p}=0.12$, statistically not significant).

Table 2 shows the distribution of the sedation and anxiolysis score after medication among two Groups A and
Group B respectively. Measurable sedation or clinical sedation per OAA/S scale was observed at every 15 minutes after administration of premedication. Out of 30 cases, 26 (86.6\%) shows measurable sedation, i.e. $\leq 17$ score at 30 minutes of sublingual midazolam administration in Group A. While 18 (60\%) cases out of 30 from Group B shown measurable sedation at 30 minutes of oral midazolam administration. These association was statistically significant $(\mathrm{p}=0.03)$.

Also, anxiolysis score among the two groups were measured at every 15 minutes after administration of premedication. The results show that $28(93.3 \%)$ participants of Group A shown satisfactory anxiolysis score, i.e. $\geq 3$ as compared to $20(66.6 \%)$ for the Group B at 30 minutes of administration. This association is statistically significant $(\mathrm{p}=0.02)$.

Post-operative Nausea Vomiting (PONV) was observed among $4(13.3 \%)$ cases from sublingual midazolam administered Group A, while 3 (10.0\%) from oral midazolam Group B. This association was not statistically significant. $(\mathrm{p}=1.00)$.

\begin{tabular}{|c|c|c|c|c|}
\hline $\begin{array}{l}\text { Sr. } \\
\text { No. }\end{array}$ & Variables & $\begin{array}{c}\text { Group } \\
\text { A }\end{array}$ & $\begin{array}{c}\text { Group } \\
\text { B }\end{array}$ & $\begin{array}{c}\mathbf{P} \\
\text { values* }\end{array}$ \\
\hline 1 & $\begin{array}{r}\text { Age (yrs.) } \\
\text { Mean } \\
\text { S.D. } \\
\text { Range }\end{array}$ & $\begin{array}{c}32.6 \text { yrs. } \\
5.2 \\
27-55\end{array}$ & $\begin{array}{c}34.8 \text { yrs. } \\
7.1 \\
29-57\end{array}$ & $\mathrm{P}=0.14$ \\
\hline 3 & $\begin{array}{r}\text { Weight }(\mathrm{kg}) \\
\text { Mean } \\
\text { S.D. } \\
\text { Range }\end{array}$ & $\begin{array}{c}53.08 \\
7.43 \\
40-60\end{array}$ & $\begin{array}{c}51.15 \\
9.18 \\
32-58\end{array}$ & $\mathrm{P}=0.12$ \\
\hline 3 & $\begin{array}{r}\text { Pulse rate (Preop.) } \\
\text { Mean } \\
\text { S.D. } \\
\text { Range }\end{array}$ & $\begin{array}{c}78 \\
13.2 \\
62-88\end{array}$ & $\begin{array}{c}81 \\
14.6 \\
64-90\end{array}$ & $\mathrm{P}=0.21$ \\
\hline 4 & $\begin{array}{r}\text { Mean BP (Preop.) } \\
\text { Mean } \\
\text { S.D. }\end{array}$ & $\begin{array}{l}88 \\
10\end{array}$ & $\begin{array}{l}92 \\
12\end{array}$ & $\mathrm{P}=0.35$ \\
\hline 5 & $\begin{array}{r}\text { Spo2 (Preop.) } \\
\text { Mean } \\
\text { S.D. }\end{array}$ & $\begin{array}{c}98.1 \\
0.9\end{array}$ & $\begin{array}{c}98.3 \\
1.0 \\
\end{array}$ & $\mathrm{P}=0.18$ \\
\hline & Clinico-Sociod & raph & $\begin{array}{l}\text { ofile } \\
B\end{array}$ & $s$ \\
\hline
\end{tabular}

$*_{t}$ test. The two-tailed $\mathrm{P}$ value is used. $\mathrm{P}>0.05$ is considered statistically significant (SS).

\begin{tabular}{|c|c|c|c|c|}
\hline $\begin{array}{l}\text { Sr. } \\
\text { No. }\end{array}$ & Variables & $\begin{array}{c}\text { Group A } \\
\text { Numbers } \\
(\%) \\
\end{array}$ & $\begin{array}{c}\text { Group B } \\
\text { Numbers } \\
(\%)\end{array}$ & $\begin{array}{c}\mathbf{P} \\
\text { values* }\end{array}$ \\
\hline 1 & $\begin{array}{c}\text { Sedation } \\
\text { score } \\
\leq 17 \\
>17\end{array}$ & $\begin{array}{l}26(86.6) \\
04(13.4)\end{array}$ & $\begin{array}{l}18(60.0) \\
12(40.0)\end{array}$ & $\begin{array}{l}0.03 \\
\text { (SS) } \\
\end{array}$ \\
\hline 2 & $\begin{array}{c}\text { Anxiolysis } \\
\text { score } \\
\geq 3 \\
<3\end{array}$ & $\begin{array}{l}28(93.3) \\
02(06.7)\end{array}$ & $\begin{array}{l}20(66.6) \\
10(33.4)\end{array}$ & $\begin{array}{l}0.02 \\
\text { (SS) }\end{array}$ \\
\hline
\end{tabular}

*Fisher's exact test. The two-tailed P value is used. P $>0.05$ is considered statistically significant (SS).

\section{DISCUSSION}

The present study was conducted at a tertiary care centre located at rural area of Maharashtra. Total of 60 participants included for the study purpose; 30 participants for each group received the Midazolam sublingually $(0.5 \mathrm{mg} / \mathrm{kg})$ and orally $(0.5 \mathrm{mg} / \mathrm{kg})$ for Group A and B respectively. 
Baseline clinico-demographic characteristics were comparable between the two groups. The differences of the values between the two groups were not statistically significant. This shows study has reduced the selection bias among the two groups. The results appeared in the study could be accepted.

Sublingual route has an advantage of mucosal absorption directly into the systemic circulation with no first pass hepatic metabolism due to the rich blood supply of oral mucosa, is easy to administer, has rapid action, reliable predictable effect and the drug is not destroyed by the gastrointestinal enzymes. ${ }^{6}$ When compared to diazepam, midazolam produces a more rapid onset, a slightly shorter duration and perhaps a greater degree of amnesia. ${ }^{7}$ Premedication with midazolam has shown to be more effective than parental presence or placebo in reducing anxiety and improving compliance at induction of anaesthesia. ${ }^{8}$ In this study, 86.6 percent of the Group A cases achieved the clinical sedation score $\leq 17$ after 30 minutes of administration of sublingual midazolam, while 60 percent from the Group B achieved the same score at 30 minutes $(p<0.05$, Statistically Significant). More than 50 percent achieved the sedation within 15 minutes of administration of the Midazolam to the Group A.

Shobhana Gupta et al studied $66.6 \%$ of the patients in the sublingual group found sedation score satisfactory as compared to $53.3 \%$ in the case of group receiving tablet of midazolam. ${ }^{8}$ The sedation score was measured at 30 and 45 minutes and among the paediatric cases. Brosius KK and Bannister CF observed, in a sample of healthy pre-adolescents and adolescents, clinically detectable sedation $(\mathrm{OAA} / \mathrm{S} \leq 17)$ in merely $40 \%$ of patients even at higher doses (20 mg) of oral midazolam. ${ }^{9}$ Midazolam administered orally metabolized through the first pass metabolism, which may interfere with the action for sedation. However, Yeo Sw et $\mathrm{al}^{3}$ concluded in their study that general anaesthesia is more efficacious and safer than sedation in patients scheduled for minor gynaecological procedures, as it has a greater tendency to perioperative oxygen desaturation $(18 \%$ of sedated $(p<0.01)$ had oxygen saturation of less than $85 \%$ ) by using Midazolam intravenously for sedation.

One must be particularly careful when administering any drug intravenously, Benzodiazepines in general and midazolam in particular are more likely to produce respiratory and cardiovascular depression. ${ }^{4}$ But non-significant change in arterial pressure, oxygen saturation significantly at any time after premedication, induction or in the postoperative period in a study conducted with use of oral midazolam as a premedication for sedation. ${ }^{8}$

In the present study, score for anxiolysis was also observed (93.3\%) participants of Group A shown satisfactory anxiolysis score, i.e. $\geq 3$ as compared to $66.6 \%$ for the Group A. This association is statistically significant $(\mathrm{p}=0.02)$. Premedication with sublingual midazolam achieves significant anxiolysis at 30 minutes. Rakhi Bansal et al ${ }^{10}$ found similar findings, which shows all patients, i.e. $100 \%$ in midazolam group exhibited satisfactory anxiolytic response (Anxiolysis score $\geq 3$ ); on the other hand, only $65.7 \%$ patients achieved anxiolysis score $\geq 3$ in the control group. Karl et $\mathrm{al}^{6}$ noted that at the point of maximum anxiolysis, i.e. at $20 \mathrm{~min}$ after administration, midazolam by sublingual route had produced significant decrease in apparent anxiety in majority of the patients.
Inadequate anxiolysis was observed when Tschirch et $\mathrm{al}^{11}$ compared oral midazolam (7.5 mg) with nasal midazolam. The result may be interfered by the claustrophobia associated with MRI scan. Post-operative Nausea Vomiting (PONV) complication among the two groups studied not found significant, ( $p>0.05)$, which was similar with other studies.8,9,10

In conclusion moderate sedation, i.e. conscious sedation and satisfactory anxiolysis was achieved more effectively through sublingual route as compared to oral route of midazolam for minor gynaecological procedures without significant side effects.

\section{REFERENCES}

1. Golinski MA. Understanding conscious sedation in the operating room. Plast Surg Nurs 1998;18(2):90-3, quiz 94-5.

2. Goetzl LM. ACOG committee on practice bulletinsobstetrics. ACOG practice bulletin. Clinical management guidelines for obstetrician-gynaecologists. Number 36, July 2002. Obstetric analgesial and anaesthesia. Obstet Gynaecol 2002;100(1):177-91.

3. Yeo SW, Tay D, Chong JL, et al. General anaesthesia vs sedation for minor gynaecological procedures-a comparative study. Singapore Med J 1993;34(5):395-8.

4. Daniel E Becker. Pharmacodynamic considerations for moderate and deep sedation. Anaesth Prog 2012;59(1):28-42.

5. Greenblatt DJ, Harmatz JS, von Moltke LL, et al. Age and gender effects on the pharma-cokinetics and pharmacodynamics of triazolam, a cytochrome P450 3A substrate. Clin Pharmacol Ther 2004;76(5):467-79.

6. Karl HW, Keifer AT, Rosenberger JL, et al. Comparison of safety and efficacy of intranasal midazolam or sufentanyl for preinduction of anaesthesia on paediatric patients. Anaesthesiology 1992;76(2):209-15.

7. Wright SW, Chudnofsky CR, Dronen SC, et al. Comparison of midazolam and diazepam for conscious sedation in the emergency department. Ann Emerg Med 1993;22(2):201-5.

8. Shobhana Gupta, Hina Gadani, Shravan Kedia. Is premedication with midazolam more effective by the sublingual than the oral route? Anaesth Essays Res 2011;5(1):43-7.

9. Brosius KK, Bannister CF. Oral midazolam premedication in preadolescents and adolescents. Anaesth Analg 2002;94(1):31-6.

10. Rakhi Bansal, Anjum S Khan Joad, Meenakshi Saxena, et al. Oral midazolam is a safe and effective premedication in adult outpatients undergoing brachytherapy for cancer cervix under general anaesthesia: a prospective randomised, double blind placebo-controlled study. Indian J Anaesth 2015;59(7):437-9.

11. Tschirch FT, Göpfert K, Fröhlich JM, et al. Low-dose intranasal versus oral midazolam for routine body MRI of claustrophobic patients. Eur Radiol 2007;17(6):140310. 